\title{
Correction: Design and synthesis of tetrahydrophthalimide derivatives as inhibitors of HIV-1 reverse transcriptase
}

\author{
Ashok Penta', Swastika Ganguly ${ }^{2}$ and Sankaran Murugesan ${ }^{1 *}$
}

\author{
*Correspondence: murugesaa789@ \\ gmail.com \\ ${ }^{1}$ Department of Pharmacy, Birla \\ Institute of Technology \& Science, \\ Pilani Rajasthan 333031, India \\ Full list of author information is \\ available at the end of the article
}

It has been drawn to the publisher's attention that this article [1] was inadvertently published with certain omissions. The authors apologize for the omissions in the published article.

The co-authors Nicolas Sluis-Cremer and Brian D. Herman, Division of Infectious Diseases, Department of Medicine, University of Pittsburgh School of Medicine, Pittsburgh, PA 15261, USA have now been added as co-authors.

The following sentence has been added to the acknowledgements section: "The research in the N.S.-C laboratory was supported by a grant from the United States of America National Institutes of Health (GM068406)"

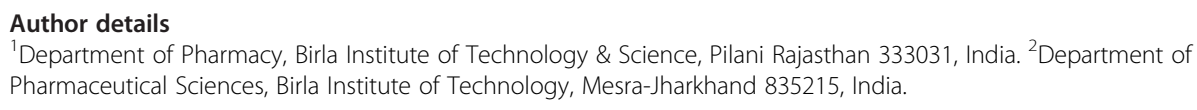

\section{References}

1. Penta et al (2013) Design and synthesis of tetrahydrophthalimide derivatives as inhibitors of HIV-1 reverse transcriptase. Organic and Medicinal Chemistry Letters 3:8

doi:10.1186/2191-2858-3-12

Cite this article as: Penta et al:: Correction: Design and synthesis of tetrahydrophthalimide derivatives as inhibitors of HIV-1 reverse transcriptase. Organic and Medicinal Chemistry Letters 2013 3:12.

\section{苗

(c) 2013 Penta et al.; licensee Springer. This is an Open Access article distributed under the terms of the Creative Commons Attribution License (http://creativecommons.org/licenses/by/2.0), which permits unrestricted use, distribution, and reproduction in any medium, provided the original work is properly cited. 